\title{
La técnica como entre-dos. Por un enfoque del trans-hacer*
}

\author{
Daniel Sibony * $^{*}$ \\ Traducción del francés al español \\ de Luis Alfonso Palau Castaño \\ DOl: 10.22395/csye.v6n11a11
}

Entre decir y hacer; pensar la técnica. Tales son el título y el sub-título de mi investigación que trata de aportar herramientas nuevas para pensar la técnica, la técnica en tanto que imagen real de nuestros diálogos con el mundo; imagen real, pero sobrecargada de fantasmas y capaz de suscitar por ello, de despertarlos, al infinito. Una de las cuestiones que yo abordo allí -y que importa sobre todo por sus aplicaciones- es, entre otras, la de comprender el proyecto de hacer, que sea necesidad o deseo: lo que empuja la humano a hacer, a em-prender, a lanzarse a una técnica; y el extraño fenómeno que ocurre yo lo llamo trans-hacer (trans-faire).

Un proyecto de hacer es, ante todo en su comienzo, lo que busca responder a la angustia de estar ante lo que no se puede hacer (infaisable), lo imposible. Cuando se dice: "ponete a hacer alguna cosa, cogé oficio, ino te quedés ahí!" es un llamado a no permanecer idéntico a sí mismo, es el llamado a buscar una alteración, una alteridad, para relanzar el juego, el juego de ser y de vivir. Por supuesto que esto exige ser "administrado", y "gestionar" es infiltrar en todas las zanjas o tripas de nuestra lengua. Incluso si les llega una carta de amor que

Tomado de Prades, Jacques (1992). La tecnociencia. Las fracturas de los discursos. París: L'Harmattan Capítulo X: El diálogo entre el hombre y la técnica (pp. 247-263). Traducción del francés al español por Luis Alfonso Palau Castaño, Medellín, abril 2017. Nota del editor.

** Matemático, psicoanalista, filósofo, ha publicado entre otras: El Grupo inconsciente: el vínculo y el miedo. Paris: Ch. Bourgois, 1980. La judía, una transmisión de inconsciente, 1983. El Amor inconsciente, más allá del principio de seducción, 1983. Goces del decir, nuevos ensayos sobre transmisión de inconsciente, 1985. Perversiones. Diálogos sobre locuras “actuales", Grasset, 1987. Lo femenino y la seducción, 1987. Con Shakespeare. Estallidos y pasiones en doce piezas, Grasset, 1988. Escritos sobre el racismo. París: Bourgois, 1988. Entre decir y hacer. Pensar la técnica. París: Grasset, 1990. Entre-Dos. El origen compartido, Seuil, 1991; De lo vivido y de lo invivible. Psicopatología de lo cotidian. ${ }^{\circ}$ Albin Michel, 1992. (1992) Sobre el pecado original. Los tres monoteismos: judaismo, cristianismo, islamismo; entre sus fuentes y sus destinos. Madrid: Síntesis, 2014. El Pueblo "Psy". París: Balland, 1992. Acontecimientos II. Psicopatología de lo cotidiano, 1995. El racismo o el odio identitario. París: Bourgois, 1997. Fantasmas de artistas. París: O. Jacob. Islam, fobia, culpabilidad. París: O. Jacob. Psicoanálisis y judaismo, 2001. De la Identidad a la Existencia, aporte del pueblo judío. París: O. Jacob. Próximo Oriente, psicoanálisis de un conflicto. París: Seuil, 2003. El enigma antisemita. Paris: Seuil, 2004. El Cuerpo y su danza, 2005. Los Sentidos del reír y del humor. París: O. Jacob, 2010. ¿Don de sí o comparti de sí?, el drama Levinas. Paris: O. Jacob. El Odio del deseo. París: Ch. Bourgois. Nombre de Dios. Más allá de los tres monoteismos. París: Point, 2006. Locos del origen, diario de intifada. París: Seuil. Creación. Ensayo sobre el arte contemporáneo. París: Seuil, 2005. El envite de existir; análisis de las terapias. París: Seuil, 2017. Nota del traductor. 
los trastorna un poco, ustedes dicen: "no sé cómo manejar esto". "Gestionar" y "gestión" surgen por todas partes en el lenguaje; esas palabras vienen de gesto. Es el gesto por el que se trata de quebrar esta identificación consigo mismo, abrir un campo de desbordamiento, un cierto campo imaginario y de fantasmas, sin que la rotura de identificación sea demasiado abierta. Todo esto está al comienzo. Pero en proyección, río abajo, ¿qué se encontrará? Se encuentra un deseo de llevar ese "hacer" -esa cosa fabricada, ese sistema, ese protocolo, esa disposición- hasta sus propios límites. O dicho de otra manera: el impulso que empuja a hacer, empuja a trans-hacer. Esto puede parecer un juego de palabras gratuito con lo que se llama la transferencia en psicoanálisis. En realidad, lo que se llama transferencia en psicoanálisis es el secreto de lo que está en juego en todo proyecto de hacer. ¿Qué es la transferencia? A partir del sentido freudiano, yo le doy un sentido más amplio en un capítulo que llamé "La máquina transferencia". La transferencia es el hecho de que dos entidades en presencia, y en estado de "hablarle" la una a la otra, instauran de entrada un mecanismo por el que lo no-dicho del uno entra en resonancia con los silencios del otro, y luego con su decir. Esto induce un segundo diálogo, de suerte que se está de entrada a cuatro cuando son dos los que hablan. Se puede objetar que esto pasará en los dispositivos psicoterapéuticos, donde se escucha a alguien que viene a deciros cosas. Yo sostengo que el fenómeno es mucho más vasto. Al comienzo yo era investigador en matemáticas, y la idea de un diálogo del investigador con su material me parece esencial, punzante. Es la localización de dos dispositivos lógicos: el saber matemático y la disposición progresiva de un real que toma forma. La investigación matemática es altamente técnica. Las ciencias también son técnicas, en el sentido en que yo la entiendo: dispositivos de lenguajes que pueden funcionar "completamente solos". Si se buscan sistemas que funcionen completamente solos, no es para irse a descansar; es porque se está fascinado por el deseo de producir alguna cosa que sea una verdadera memoria, que no solamente retenga las marcas que uno le hace, sino que se retenga ella misma para seguir un cierto trayecto. Por supuesto que esto tiene sus inconvenientes. Uno cree que el diálogo pues del matemático con su dato se reduce a esto: él sabe o no sabe; la materia se entrega o no; entra en ecuación o no. En realidad, la investigación pone en juego un estado en el que el matemático trata de transmitir informaciones a esa materia matemática en ebullición, de manera que ella responda, sin "saber" demasiado a qué responde. Y el punto álgido de una investigación es instaurar ese espacio de transferencia en el que se está en una cara a cara en espejo, uno mismo y su problema. Pues entonces se fija a tal punto el problema que uno mismo se encuentra fijado, por tanto inmóvil, inmóvil psíquicamente. Ahora bien, se trata precisamente de introducir una dinámica de transferencia por medio de la cual lo no-dicho, o lo indecible, aparezca y se engrane... 
Otro ejemplo, el de la procreación asistida. Con frecuencia me llaman a pedir mi opinión, a hablar con los que trabajan en el hospital sobre estos problemas, que reciben mujeres llamadas estériles, que los manejan o que los enredan, que les hacen fecundación in vitro y otras cosas sofisticadas. Algunos han lanzado alertas: ¿no será que vamos hacia una procreación asexuada, hacia una maternidad solitaria en que la madre, completamente sola, con el embrión en su mochila, va a hacérselo implantar? Y uno se da cuenta, escuchando al personal de salud y a las mujeres, que de hecho esas técnicas instauran un espacio donde los fantasmas de los unos y de las otras pueden decirse y transferirse. Y se descubre que esos fantasmas son los de nuestros ancestros, del mismo orden que aquellos que reportan los textos antiguos. ¿Qué mujer no ha tenido algún día el fantasma de poder procrear completamente sola, con su hombre ideal, Dios Padre de preferencia? Hace dos mil años se escribió un bellísimo libro a partir de esto, que se llama el Evangelio. Los fantasmas no datan del momento en que se enchufan las máquinas sino -y esto exige una cierta humildad- esos montajes técnicos son lugares de transferencia, hacen aflorar fantasmas. Los no-dichos entran en comunicación; y es cuestión de amor: cuando se transfiere a alguien se alcanza con él, por represión interpuesta, un diálogo secreto que uno no se atreve a tener abiertamente ni con él ni consigo. Es el rasgo elemental del amor. Si amáis es porque el otro está más allá de vos, por fuera de usted. Es por esto que los matrimonios muy estabilizados, en los que ninguno está por fuera de sí durante años, son pymes, pequeñas o medianas empresas que tienen más que ver con el contrato que con el amor. Por supuesto que el mérito de esas técnicas (de la PMA, procreación médica asistida) no es solamente de ayudar, o de hacer emerger fantasmas hasta entonces reprimidos. Como toda técnica, su mérito es plantear de manera urgente la cuestión de la transferencia: la trans-ferencia de los fantasmas y el trans-faire de las técnicas. A veces el paso al acto o el accidente se impone como única salida; y entonces precisamente se bloquea la transferencia; se requerirá intentar otras técnicas, otras transferencias que corren siempre el riesgo de entrar en el mismo callejón sin salida...

La idea que me sirve para abordar la dimensión inconsciente que está en juego en las técnicas es este impulso a hacer por otra cosa distinta al placer de dominar el mundo. Descartes decía: "el hombre sería como amo y poseedor de la naturaleza"; era astuto y poco cartesiano. El proyecto no es volverse amo y poseedor de la naturaleza, porque de cierta manera, se tiene bastante que hacer, uno no domina tanta cosa. Por la técnica el hombre trata de producir un hacer que dé lugar a un trans-hacer, a un más allá, de manera que pueda ponerle una cita a lo que de él mismo se le escapa. La fascinación sería precisamente producir esa cosa, por ejemplo, este ordenador, que él solito rectificara no solamente los errores del programa sino que cambiara de problema porque ese problema no tiene ningún interés. Dicho de otra manera: el famoso miedo que se agita, 
ese del hombre ante su técnica, miedo a que su técnica se le escape, miedo a la deshumanización, no es sino la expresión enloquecida de un fantasma precioso, por medio del cual el hombre se da cita -gracias a un hacer, un lenguaje, una memoria- se da cita precisamente allí donde el lenguaje que ha desatado, y que encarna esta máquina, puede sorprenderlo, sorprenderse y llamar a que arranque otro lenguaje, otra transferencia renovada de lenguaje.

Y esto aclara de paso ese fenómeno crucial que se ha llamado "accidente". Los accidentes son esos momentos singulares, esos puntos catastróficos por los que una máquina, de repente, no hace lo que se espera de ella. No es tan simple. Si uno considera el accidente de aquel Airbus que su piloto no logró enderezar, se ve que el comandante de abordo era un instructor veterano, que conocía mejor que nadie los detalles, las normas, el número de segundos exacto para que la orden tuviera efectos. Sin embargo, hubo un accidente. Es aquí donde uno apercibe la relación mágica del hombre con sus objetos. Pues la técnica toma su fuente en la magia, en el delirio de convocar el más allá y de tener con él un diálogo sostenido. El más allá bien pueden ser los demonios que nos enferman. Cuando ya no se tiene más necesidad de demonios, uno se toma el antibiótico que os corta la enfermedad; de suerte que uno camina por la calle con su enfermedad al lado, ni siquiera se puede ya dialogar con ella porque hay una pared de vidrio entre los dos y, cuando la enfermedad se fatiga, ella os abandona, uno se cura, sin a veces haberla conocido... a la enfermedad... En todo caso, la relación mágica siempre es actual bajo forma de fantasmas. Pienso que el piloto se dijo: "Conozco muy bien las normas, pero ila máquina no me va a hacer esto a mí!". Para comprender estas relaciones de ternura, es necesario ver cómo la gente le habla a sus máquinas. Un día, yo vi a un cerrajero echarle carreta a la cerradura que estaba intentando abrir en mi casa. Entonces se puso a hablarle como una muchachita de la que fuera su padre, y ella marchó. Nadie duda: la magia es una manera de instaurar un relé de transferencia, al comienzo muy racional, para prolongar un diálogo consigo mismo -con su "otro"- al que no se puede tener directamente.

De esta manera, los accidentes aparecen como puntos singulares, rupturas de diálogo entre el hombre y su máquina, o su "machin" <"esa vaina", cosa que no se quiere o que no se puede decir, poco conocida o poco recordada>. En el ejemplo del tren loco que entra en la estación, el tren es todo un proceso, en su origen con gentes que han hablado con la materia para fomentar ese proceso, para disponer su funcionamiento, y gente que, al final, va a mantenerla, a dialogar con ella; es también eso, el mantenerla (l'entretien), incluso se dice: tener un entretien (una conversación)... Para que un tren loco entre en una estación, es necesario que al menos tres o cuatro personas hayan tenido lo que yo llamo instantes-bof en el diálogo con él: manera de eludir la plática. Dicho 
de otro modo: ellos mismos cayeron en la trampa de haber creído que el objeto era un objeto-memoria que podía continuar ronroneando. Ahora bien, él lo es, pero la memoria recuerda; ella se recuerda y os recuerda. Pero ellos pues cayeron en la trampa de un ideal fantaseado en el que se producirían cosas que se nos escapan porque no tenemos necesidad de dirigirlas constantemente. Pero hay un momento en que esta memoria que se acuerda quiere un contacto más "caluroso", más presente. O dicho de otra forma: hay un llamado al diálogo, a otro nivel del diálogo. Se tiene la impresión de que una pulsión de muerte ha agarrado al hombre, el conductor; una pulsión de muerte no es una pulsión de matar de ninguna manera, es una pulsión de desconectarlo todo, de reencontrarse en sí, en una burbuja, una especie de autogestion mortífera. Esa pulsión de muerte lo ha cogido'; algo le ha hablado, y él no tenía el corazón para responder, quizá tenía el corazón en otra cosa, o quizá no tenía corazón del todo, pero lo que sí es seguro es que la cuestión del llamado se plantea, por tanto, de un relanzamiento del deseo y del diálogo, incluso con máquinas banalizadas, como una locomotora.

A partir de acá se abren perspectivas. Si hablé del accidente-es una reflexión sobre el accidente con la que comienza este Entre decir y hacer-es para mostrar que incluso en un diálogo bastante estabilizado con la máquina o la técnica, de repente el Otro -la alteridad- viene a recordar y decir: atención, el objeto o la máquina, o el sistema, es un proceso; ¿dónde estás tú en el proceso? Y es ahí donde el libro aborda esa dimensión creativa de la técnica, es decir, del hacer humano, de lo que se hace; pues incluso para hacer un poema se requiere de la técnica, eso requiere una técnica para poder pasar de largo, para poder no aplicarla. Esas son las técnicas más difíciles; uno debe poder convocarlas, tenerlas todas ahí, y cortar con ellas, para oscilar sobre un vacío donde es el Otro el que va a hablar, donde es la transferencia inconsciente la que va a actuar y a expresarse. El psicoanálisis, la práctica terapéutica también exigen una habilidad verdaderamente digna de respeto porque acumulan conocimientos que vienen de lejos, conocimientos subterráneos, y al mismo tiempo exigen la capacidad de no servirse de ellos; se diría que el Otro, el síntoma, el inconsciente, hace a veces prueba de un pudor espantoso y quiere que la cosa se pase, que el desenlace tenga lugar sin deberlo. Eso ocurre. Hay gentes que se ponen de repente mal porque irían bien si aceptasen que deberían ir bien. Y si la problemática de la deuda es precisamente lo que los mina, lo que los atrapa por las tripas, es demasiado pedirles que se curen por medio de su enfermedad. Se requieren ciertas desviaciones, ciertos descarríos, algunas técnicas también...

Imposible no recordar esa sublime película de Kurosawa, Dodeskaden... (1970) la onomatopeya de la locomotora viviente en que la pulsión de muerte convirtió a aquel pobre hombre... https://www.youtube.com/ watch? $\mathrm{v}=$ N8dObK2oWw. Nota del traductor. 
Uno se vuelve una bestia frente a las técnicas cada vez que se elude la cuestión del lugar en el cual uno está con respecto a ellas, es decir la cuestión de la transferencia <transfert>; que el libro generaliza el trans-fer <el transfaire, trans-hacer>; también con esta proposición concreta, casi digna de un ministerio: ¿es usted capaz, todas las veces que utiliza una técnica, de hacer el análisis transferencial de las fuerzas que están presentes en torno a esa técnica? Y esto llega lejos pues en esas técnicas de procreación que yo evocaba se le puede decir: "entonces, ella está encinta, eso prendió, pero ahora ella tiene seis embriones y habrá que retirarle tres o cuatro o cinco. ¿Cuáles retirar?" Y el médico psicologizante llega también con sus fantasmas: "es horrible, me recuerda la Elección de Sofía, esa novela en la que una mujer que llega a Auschwitz, un nazi le pregunta que escoja inmediatamente a quien se va a matar, a quién se va a gasear de primero, a su hijo o a su hija. Y ante esta elección evidentemente ella enloquece. Acá estamos en presencia de seis hermanos en el útero, se va a escoger cuál de los embriones va a sobrevivir...". El médico así proyectaba su fantasma, ponía a funcionar su transferencia, es su derecho, pues es un ser humano, pero acá rehusaba el análisis. Erigía su fantasma en límite "objetivo". Ahora bien, la humanidad, tal como ella es, acepta desplazar los límites y renovar las apuestas; acepta dejarse superar por lo que ella misma ha producido. Es un acto de generosidad el que se ofrece, y no solamente de seguridad contra la molestia. Simplemente, se trata de estar cada vez a la altura del desafío, que regresa siempre de frente, y que es vuestro producto. El primer acto de este desafío es ser capaz de analizar la transferencia en la que uno se encuentra con respecto a ese dato.

Al comenzar esta investigación yo escribía un libro sobre Heidegger que se quedó en plan; y su pensamiento sobre la técnica me ha fastidiado a tal punto que eso me incitó a escribir lo que yo pensaba de la técnica, y después eso hizo una especie de bolsillo que creció cuatrocientas páginas y que se desprendió, a partir pues de una crítica de la reflexión filosófica sobre la técnica, especialmente la de Heidegger (los otros no han hecho más que seguir). Lo que dice Heidegger es interesante porque él hace ante todo un esfuerzo -ya en Ser y tiempo- un esfuerzo loable para pensar lo que es una herramienta, lo que es la relación del hombre con lo que está (como él lo dice) al alcance de la mano, o a la mano. Pero la técnica, él no la conoce. No practicó nunca una técnica y, especialmente, no conoce ese milagro por el cual uno pone en su lugar una disposición en la que solo hay entidades inertes, pero de las que uno espera, cuando menos, algo, como una inspiración, algo que testimonie que ese montaje de lenguajes se inspira, toma su aliento en otra parte, pues toma contacto con el espacio, el abismo, el vacío, el cosmos, las fuerzas cósmicas. Heidegger no conoce eso; para él, una técnica es cálculo. Objeta que existe pues lo incalculable, pero él no sabe que un verdadero cálculo en el sentido fuerte del término, en el sentido 
de una teoría matemática de punta, toma su raíz en lo incalculable, para aparecer. Por ejemplo, para demostrar que el axioma de elección es equivalente a la existencia de un buen "orden" en un conjunto -hago pues un poco de teoría de conjuntos- es necesario utilizar el hecho de que el universo de los conjuntos no es un conjunto; y por aquí tocamos con el dedo el soporte de lo que llamamos "lo indecidible" en matemáticas. Las decisiones que se hacen aparecer, y que se llaman teoremas, se apoyan en el abismo, en el vacío, en un indecidible. Dicho de otro modo: su concepción del cálculo es demasiado pobre. Pero lo interesante de su crítica, como de las otras críticas que en él se inspiran, al estigmatizar la técnica por su insuficiencia, despliega el fantasma de una técnica que ella sí fuera suficiente, una técnica de la que no podríamos decirle nada. ¿Qué sería ella pues? Una técnica totalitaria. Pero para ello Heidegger conoció la fascinación sincera de ver una máquina técnica perfecta. ¿Cuál? La máquina social del nazismo. Incluso si luego retrocedió, para ir a ver a otra parte... ¿Por lo demás que hizo Heidegger luego de su ruptura con el nazismo? Se fue a hundirse en las fuentes presocráticas de la filosofía occidental para mostrar que la vocación de Occidente es ir a encarnarse en el origen griego que los griegos mismos nunca encarnaron claramente. Se fue a hacer el eugenismo consecuente.

Esto no quiere decir que mi libro esté centrado en Heidegger; a pesar del lugar que se le hizo en algunos medios limitados, ese pensador no es sino un aspecto de una crítica bastante limitada de la técnica, una crítica que le reprocha sus insuficiencias, mientras que son ellas las que la hacen vivir y la protegen de la locura.

Mi libro no es pues un alegato contra los enemigos de la técnica, puesto que ellos también -y yo lo demuestro- tienen que ver con la técnica y con un fantasma bastante punzante, el de una transferencia sobre una técnica a la que no habría nada que decirle. Ahora bien, es la insuficiencia de las técnicas la que las nutre <la importancia de los defectos>, que no solamente las estimula, sino que las llama a que se tropiecen, a que se rompan la crisma en sus límites; y es así como ella desplaza la cuestión del límite. Cuestión del límite que es la del lenguaje, el límite de lo decible; y es en este sentido que una técnica, cualquiera ella sea, si es un poco fuerte y consecuente, es una cita que el hombre se pone con el origen del lenguaje. Ciertamente no es un asunto de captar el origen del lenguaje, puesto que es al precio de su pérdida que el lenguaje adviene. Asimismo, no es asunto de aprehender el origen de la técnica porque se caería sobre una herramienta única, que solo es una herramienta y ni "herramienta" es. Los monos pueden hacer una herramienta única, o incluso dos, pero sin poderlas articular con las terceras. Se ha descubierto que algunos llegan a un aprendizaje al final de cuatro años; quizá algún día irán a la escuela, lo que probará que no es la escuela lo que especifica lo humano, pero otra cosa será "salir" de la 
escuela, por ejemplo. Una sola herramienta pues, todo como una palabra que es ella sola sería un fetiche. Ahora bien, y esta es una de las ideas de ese libro, cuando se detiene el análisis de la transferencia que es un juego en una técnica, se hace de esa técnica un fetiche. En las tradiciones se trata de un objeto para capturar la divinidad. Y fuera de las tradiciones también existe: un fetiche es un objeto que se supone que capturó al "otro", el inconsciente, esa cosa que se nos escapa y, sin embargo, nos lleva. Se supone que el fetiche lo absorbió, por tanto, lo mantiene en reserva. Es evidente que esto no se mantiene mucho tiempo puesto que un buen día, el hombre, por fetichista que sea, estará hasta la coronilla de adorar eso que él mismo fabricó. Encontrará que es más directo adorarse a sí mismo, es decir encontrarse adorable. Es la versión narcisística del fetichismo. Y esto plantea la cuestión de los valores puesto que lo propio de un valor es que uno no es su autor. Imaginen la depresión de las gentes que regresan a sus casas en las noches después de haber pasado en la televisión donde les han dicho que ellos son estrellas mientras ellos saben que no lo son, puesto que fueron ellos los que hicieron el programa donde se dijo que ellos eran estrellas. Ellos querrían ser estrellas por fuerzas más lejanas. Es humano. O dicho de otro modo: uno tiene necesidad de ese más allá en el seno mismo de los tratamientos técnicos, y es por esto que yo no opongo en ningún momento la trascendencia y la técnica. Y esto parece ser que innova con respecto a los enfoques que han circulado hasta ahora.

Estos últimos no quedan anulados, sino situados; recuperan otro sentido. Por ejemplo, la idea de que existe un origen biológico de las técnicas, es decir, que el hombre fabrica técnicas porque refleja lo que ocurre en su cuerpo. Esto no es falso, ni siquiera es falso; es evidente que una célula es una máquina, una fábrica, una monstruosidad técnica tal, que ha sido solamente en estos últimos años cuando nos hemos dado cuenta de que en efecto nuestras más grandes fábricas o memorias comienzan apenas a aproximársele, y de bien lejos. La idea se reduce pues a un fantasma interesante: el hombre proyecta su cuerpo en las técnicas. Esto se integra en mi discurso como un caso particular; el hombre proyecta sus transferencias en la técnica, proyecta su alma también, su lenguaje, su proyecto de tener una memoria que lo retransmita y con la que pueda dialogar, lo que no siempre puede hacer con su propia memoria. Se podría decir que el hombre se desencadena en la técnica para tener con quién hablar, o con qué. Esto parece desesperado, pero está tan lleno de esperanza, sereno y lúdico, porque entonces uno se pone a muchos para hablar y ello ayuda a redescubrir que, ya solo uno es muchos. Uno se da cuenta de que la dinámica por la que la técnica vive-evoluciona, perece, se renueva, procrea, prolifera, conoce mutaciones-es verdaderamente el modo por el cual el viviente prolifera, cambia de lenguaje, se traduce. Finalmente la técnica aparece como un relevo de lo humano, en su ruta por alcanzar al Otro, sabiendo que ese Otro puede no ser más que una de sus 
imágenes. Cuando se dice que uno está rodeado de máquinas, de técnicas, es la reacción narcisística normal de alguien que se siente rodeado de demasiadas imágenes suyas. Se quiere un poco de respiro, se quiere cambiar de imagen; uno de los nervios del desarrollo técnico es el deseo de renovar sus propias imágenes, lo que supone una dimensión imaginaria bastante viva. Es precisa mucha imaginación para hacer matemáticas, no una imaginación de personajes sino de situaciones, de relaciones de cuerpos, de disposiciones de espacios, de construcción, de arquitectura hecha de letras, de tensiones, de flujos... Y es nuestra manera de renovar un gesto que es quizá el gesto fundador de la humanidad, a saber: el don del lenguaje. Produciendo algo que se pone a vibrar y a tener su vida propia, su memoria, una cierta autonomía, se renueva un acto por el cual un lenguaje nos es dado; es algo más que la constatación aburrida de que "nos bañamos en el lenguaje". Los puntos vivos de un lenguaje son los puntos de donde se sale, dispuesto a volver a entrar de otra manera, alterado.

Se dice que la técnica domina al hombre. En lo esencial es falso, ella lo revela de otra manera. Ella lo revela dominado o presto a estarlo por un pelo, por sus síntomas de preferencia, puesto que es él el que los produce a su medida, por su deseo de ser dominado, desembarazado de sí mismo, entregado a algún dios real que se impondría en catástrofe y con toda necesidad. Esto quiere decir que no hay por qué tomar a la letra los fantasmas y los deseos que el hombre proyecta en su técnica. Puede ser que una mujer tenga necesidad de creer que ella puede procrear sola, sin hombre, para poder hacerle lugar al padre. Es la dinámica de los fantasmas que es la misma dinámica de las técnicas, o que la dinámica del decir. Algunas palabras tienen necesidad de ser dichas para que otras, palabras completamente distintas, puedan ser dichas. Alguien tiene necesidad de insultarlo, para poder luego decirle que él puede hacer cosas con usted. Evidentemente, si uno está apurado y corta en el preciso momento del insulto, eso quiere decir que uno fetichiza la relación o que él la ha fetichizado, pues también él puede ser víctima del relevo que ha querido introducir, pero no lo ha podido saltar y se encunetó en un punto-frontera. Dicho de otro modo: la técnica no es en realidad un instrumento, sino una modalidad por la que el ser se remueve, se trabaja, para emerger a niveles menos arduos, que serían niveles de la letra, de la literatura, de lo que se ofrece a las manos y a las palabras para ser manipulado, modulado, transformado, para ser dado y vuelto a donar de otro modo. Es toda una erótica del cuerpo y de su presencia en el lenguaje, en el espacio-tiempo.

P. S. Para responder a las preguntas que plantea el "sombrero" de este texto:

1. El "accidente" (de tipo catástrofe o encuentro, por tanto negativo o positivo) es la fuerza más importante para destotalizar una técnica, libre para 
abrirla al fantasma de una totalidad por venir..., hasta que se presente un próximo accidente o nuevos hallazgos.

2. El hecho de que un fantasma se realice gracias a las técnicas no lo agota como fantasma (ver el fantasma de "volar", sus variantes son tan numerosas y siguen estando abiertas). Cuando el fantasma se agota o es arrancado, se sigue la violencia, la misma que se le imputa a "la técnica", pero rara vez sin recursos. El devenir-realidad, a su vez, produce nuevos fantasmas; revela también hasta qué punto realidad y fantasma comunican, se pertenecen, se recortan. Los grandes pensadores siempre lo han sabido (ver la idea clásica del carácter ilusorio de nuestra realidad)

3. Todas las veces que la técnica se ha revelado totalitaria, es porque el espíritu de los que la sirven, ya lo era. Y los que la denuncian, con todo el derecho, temen ver su espíritu volverse también...

Todos estos "puntos" están, por supuesto, debidamente tratados en Entre decir y hacer. 